\title{
MAPEAMENTO DOS RISCOS FÍSICOS AOS COLABORADORES NA ATIVIDADE DO CULTIVO DE MANGA EM IPANGUAÇU-RN
}

\author{
I. S. O. Targino, M. G. P. Viana, M. C. Bezerra, P. G. V. Sampaio e C. E. M. Jerônimo \\ Universidade Potiguar \\ isabelli_lerros@hotmail.com - mairllagermana@hotmail.com - michellecostab@hotmail.com - \\ prisamp@yahoo.com.bre c_enrique@hotmail.com
}

Artigo submetido em julho/2012 e aceito em dezembro/2012

\section{RESUMO}

A horticultura brasileira é uma das mais importantes do mundo. Além de ser o maior produtor de frutas cítricas o Brasil, ocupa posição destacada como produtor de frutas tropicais, como banana, manga, mamão, abacaxi, caju, goiaba e maracujá. Na região semiárida do Rio Grande do Norte o cultivo da manga tem seu destaque e assim como outras culturas. Essas atividades são realizadas em locais de trabalho, que pela própria natureza da atividade desenvolvida, podem comprometer a saúde e segurança do trabalhador em curto, médio e longo prazo, provocando lesões imediatas, doenças ou a morte. Desta forma, em qualquer tipo de atividade laboral, torna-se imprescindível a necessidade de investigar o ambiente de trabalho para conhecer os riscos a que estão expostos os colaboradores. Este trabalho tem como objetivo realizar o levantamento dos riscos físicos envolvidos na atividade do cultivo da manga, em caso específico para a região do alto oeste potiguar, como uma forma de contribuir na elaboração dos planos e programas de prevenção aos riscos ambientais associados a tal atividade.

PALAVRAS-CHAVE: Cultivo da manga, Riscos ambientais, Riscos Físicos.

\section{MAPPING OF RISKS PHYSICAL TO EMPLOYEES IN THE ACTIVITY OF THE MANGO CULTIVATION IN IPANGUAÇU-RN}

\begin{abstract}
The Brazilian horticulture is one of the more important in the world. Addition to being the major producer of citrus Brazil, occupies a prominent position as a producer of tropical fruits such as banana, mango, papaya, pineapple, cashew, guava and passion fruit. In the semiarid region of Rio Grande do Norte mango cultivation has its prominence and well as other cultures. Such activities are carried out in the workplace, which by the very nature of the activity, may compromise the health and safety of the worker on short, medium and long term, causing immediate injury,
\end{abstract}

illness or death. Thus, in any type of work activity, it is essential the need to investigate the working environment for learn about the risks they are exposed employees. This work has as objective carry out the survey the physical risks involved in the activity of mango cultivation in the specific case to region of the upper western of $\mathrm{RN}$, as a way to contribute to the preparation of plans and programs for the prevention of environmental risks associated with such activity.

KEY-WORDS: Cultivation of mango, Environmental Risks, Physical Risks. 


\section{MAPEAMENTO DOS RISCOS FÍSICOS AOS COLABORADORES NA ATIVIDADE DO CULTIVO DE MANGA EM IPANGUAÇU-RN}

\section{INTRODUÇÃO}

A horticultura brasileira é uma das mais importantes do mundo. Segundo Ramos (2001), além de ser o maior produtor de frutas cítricas, o Brasil, ocupa posição destacada como produtor de frutas tropicais, como banana, manga, mamão, abacaxi, caju, goiaba e maracujá. Porém, apesar dos avanços obtidos, o setor produtivo de frutas do Brasil ainda apresenta elevadas perdas e baixa qualidade, principalmente em decorrência de um inadequado gerenciamento do agronegócio, principalmente nas fases de pós-colheita e comercialização, com sérios prejuízos para os produtores e preços elevados aos consumidores (MARINO, 2002).

Dentre as culturas destacadas, a exploração comercial da mangueira no Brasil pode ser dividida em duas formas distintas. Uma é caracterizada pelo plantio de forma extensiva, com variedades locais (Rosa, Espada, Coqueiro, Ouro) com pouco ou nenhum uso de tecnologia; e a outra é caracterizada pelo elevado nível tecnológico como irrigação, indução floral e variedades melhoradas.

A cultura da manga, na região semiárida, destaca-se pelos altos rendimentos alcançados e qualidade da manga produzida. Entretanto, mesmo não sendo o maior em área e volume produzido, a cultura da manga tem grande representatividade em valores monetários, sendo a terceira cultura mais rentável do país, ficando atrás somente do melão e da uva, conforme descrevem FAO (2005), IBRAF (2006) e SECRETARIA DE COMÉRCIO EXTERIOR (2006).

A produção de manga voltada para o mercado externo exige o uso de novas tecnologias e serviços especializados, tanto no processo produtivo, quanto nas atividades póscolheita (embalagem, empacotamento e classificação). Esta cultura ainda possui uma participação significativa dos pequenos produtores, que ainda produzem de forma extensiva as variedades locais ou primitivas e, principalmente, dos pequenos fruticultores dos projetos públicos de irrigação, que até plantam as variedades do tipo exportação, mas não detém estrutura necessária para o tratamento pós-colheita e logística. Formam uma grande massa de pequenos produtores com grande capacidade de abastecimento do mercado doméstico e baixo potencial de inserção no mercado externo (EMBRAPA, 2004).

O principal eixo produtor de manga do Rio Grande do Norte compreende a plataforma frutífera do pólo Açu/Mossoró, envolvendo os municípios de Carnaubais, Ipanguaçu, Açu, Alto do Rodrigues e Baraúna, conforme ilustrado na Figura 1. A produção dos cinco municípios com manga representa $65 \%$ da produção e $68 \%$ do valor da produção do Estado. 


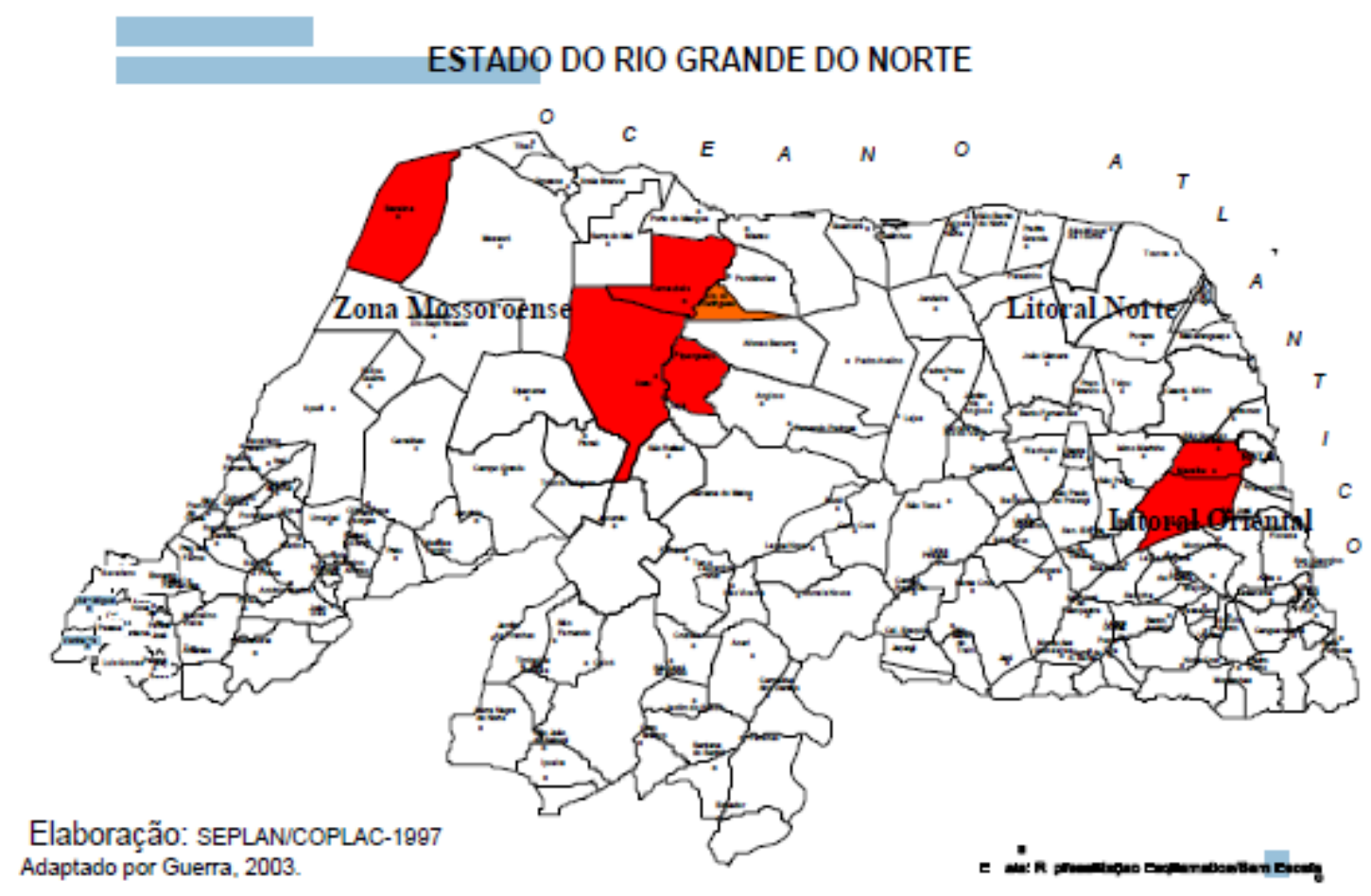

Figura 1 - Cidades Produtoras de Manga no Rio Grande do Norte. Fonte: Guerra (2003).

O cultivo da manga, assim como o de outras culturas, é realizado em locais de trabalho que pela própria natureza da atividade desenvolvida e pelas características de organização, relações interpessoais, manipulação ou exposição a agentes físicos, químicos, biológicos, situações de deficiência ergonômica ou riscos de acidentes, podem comprometer a saúde e segurança do trabalhador em curto, médio e longo prazo, provocando lesões imediatas, doenças ou a morte, além de prejuízos de ordem legal e patrimonial para a empresa. Desta forma, em qualquer tipo de atividade laboral, torna-se imprescindível a necessidade de investigar o ambiente de trabalho para conhecer os riscos a que estão expostos os colaboradores. E conforme se pode observar nos relatos bibliográficos e periódicos especializados existe uma carência de estudos específicos para tal segmento, tendo-se pequenos ensaios relativos a segurança e saúde ocupacional na agriculta em estudos como Almeida (1995), Couto (2007) e Silva et al (2011).

Logo, neste trabalho tem-se como objetivo realizar o levantamento dos riscos físicos envolvidos na atividade do cultivo da manga, em caso específico para a região do alto oeste potiguar, como uma forma de contribuir na elaboração dos planos e programas de prevenção aos riscos ambientais associados a tal atividade. Para isso, foram utilizadas técnicas de análise preliminar de perigos e riscos.

Além da corrente introdução, o artigo é estruturado a partir de uma seção dedicada a explicitar a metodologia utilizada no estudo. Em seguida, é exposta uma seção de fundamentação teórica em que são abordados os principais conceitos. Na sequência, é apresentado o estudo de caso que ilustra a utilização da Análise Preliminar de Perigos (APP) e por fim, são expostas as conclusões dos autores. 


\section{REFERENCIAL TEÓRICO}

\section{Análise Preliminar de Perigos}

A Análise Preliminar de Perigos (APP) consiste no método indutivo e é estruturada para detectar os potenciais perigos que decorrem da instalação de novas unidades e sistemas desconhecidos ou do próprio funcionamento da planta que opera com materiais perigosos. Este método tem como objetivo analisar as formas pelas quais os componentes do processo podem atuar fora de controle e de forma inesperada, elencando, para cada situação de perigos identificada, as causas, as formas de detecção disponíveis e as consequências sobre os trabalhadores, tanto no entorno na população como sobre o meio ambiente. Em seguida é executada uma avaliação qualitativa dos riscos relacionados, identificando-se, desta maneira, aqueles que necessitam ser priorizados. Além disso, a título de sugestão, incluem-se medidas mitigadoras sobre os riscos, com a finalidade de eliminar os agentes causais ou diminuir as consequências nos sistemas com acidentes identificados (ALENCAR, 2009).

A estrutura da APP envolve os eventos considerados perigosos cujas fontes tenham origem no sistema analisado, envolvendo tanto as falhas de materiais ou do sistema, como eventuais erros de operação ou de manutenção (falhas humanas). O resultado final de uma APP consiste na identificação dos perigos e no mapeamento das áreas perigosas com base nos cenários de acidente relativos aos processos, armazenamentos, instalações, transportes de produtos químicos e a outros sistemas inerentes aos processos industriais.

O uso da APP, conforme descreve Camacho (2004), associada com matrizes de aceitabilidade de risco exige que os cenários de acidente sejam classificados em categorias de frequência, as quais fornecem uma indicação qualitativa da frequência esperada de ocorrência para os cenários identificados. Esta escolha dos critérios é função do tipo de análise que se pretende executar, podendo ser definida pela entidade governamental ou pela própria empresa, quando se tratar de estudo interno. As categorias de frequência podem ser encontradas na Tabela 2.

Tabela 2 - Categorias de Frequência.

\begin{tabular}{|c|c|c|}
\hline Categoria & Denominação & Descrição \\
\hline F & Muito provável & Uma ocorrência a cada 100 anos ou mais \\
\hline E & Improvável & Uma ocorrência a cada 10 anos \\
\hline D & Remota & Uma ocorrência a cada 5 anos \\
\hline C & Ocasional & Uma ocorrência a cada ano \\
\hline B & Moderada & Uma ocorrência a cada 6 meses \\
\hline A & Frequente & Uma ocorrência a cada mês \\
\hline
\end{tabular}

Os cenários de acidente, por sua vez, devem ser classificados em categorias de severidade, as quais fornecem uma indicação qualitativa do grau de severidade das 
consequências dos cenários identificados. As categorias de severidade estão elencadas na Tabela 3.

Tabela 3 - Categorias de Severidade.

\begin{tabular}{|c|c|l|}
\hline Valor & Categoria & \multicolumn{1}{c|}{ Descrição } \\
\hline IV & $\begin{array}{c}\text { Baixo ou } \\
\text { insignificante }\end{array}$ & $\begin{array}{l}\text { - Nenhum dano ao pessoal de fábrica } \\
\text { - Pequenos danos financeiros ou materiais à empresa }\end{array}$ \\
\hline III & Marginal & $\begin{array}{l}\text { - Possibilidade de danos ao pessoal interno da fábrica } \\
\text { - Danos materiais/financeiros à empresa }\end{array}$ \\
\hline II & Crítica & $\begin{array}{l}\text { - Possibilidade de efeitos significativos sobre a integridade do público e } \\
\text { sobre a vizinhança }\end{array}$ \\
\hline I & Catastrófica & $\begin{array}{l}\text { - Possibilidade de grandes danos (vítimas fatais) ao público e à } \\
\text { vizinhança } \\
\text { - Severa degradação ambiental }\end{array}$ \\
\hline
\end{tabular}

De acordo com a Tabela 3 pode-se observar que as categorias de severidade III e IV ("insignificante" e "marginal") correspondem aos acidentes cujos danos ficam restritos às fronteiras das instalações analisadas, enquanto aqueles classificados nas categorias II e I ("crítica" e "catastrófica") correspondem aos cenários com potencial de causar danos além das fronteiras das instalações (danos ao público ou ao meio ambiente).

Combinando-se as categorias de frequência com as de severidade, obtém-se uma matriz de riscos (Figura 2), a qual fornece uma indicação qualitativa do nível de risco de cada cenário identificado na análise.

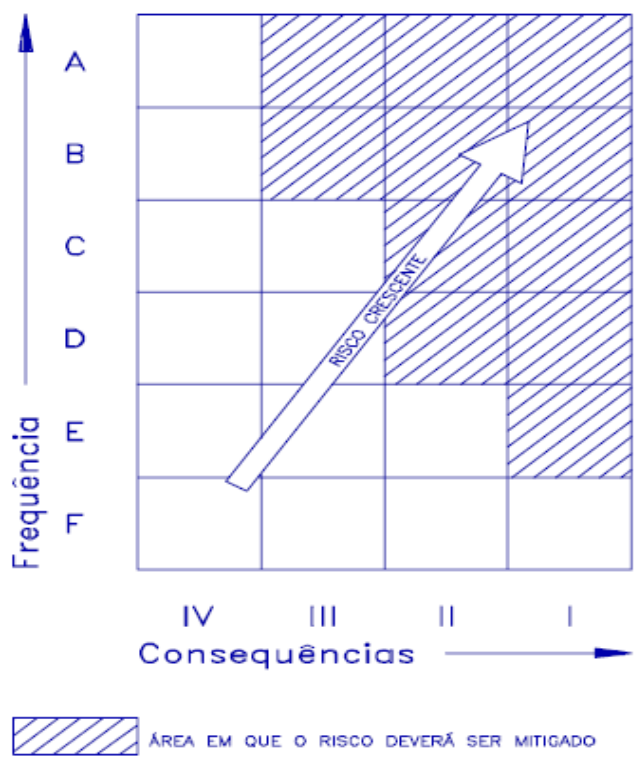

Figura 2 - Matriz de Riscos 
Os cenários de acidente localizados na área hachurada devem ser objeto de medidas de mitigação de riscos. $\mathrm{Na}$ análise deste item deve ser indicado se o cenário está dentro ou fora da área hachurada da Matriz de Risco adotada. E nesse modelo foi desenvolvida a base do presente estudo.

\section{Riscos Ambientais}

Na concepção de Ayres; Correa (2001) é considerado um risco ambiental o agente físico, químico, biológico, ergonômico e/ou de acidentes/mecânicos que possam, de acordo com a natureza, trazer ou ocasionar danos à saúde do trabalhador nos ambientes de trabalho. Sherique (2004) complementa esta definição, afirmando que para que esses sejam considerados fatores de riscos ambientais os mesmos precisam estar presentes no ambiente de trabalho, porém, em uma determinada concentração, intensidade e/ou tempo de exposição.

De acordo com a Norma Regulamentadora no 9 (NR-9) do Ministério do Trabalho e Emprego (MTE), considera-se riscos ambientais os agentes físicos, químicos e biológicos existentes nos ambientes de trabalho, que, em função de sua natureza, concentração ou intensidade e tempo de exposição, são capazes de causar danos à saúde do trabalhador. Há, ainda, os riscos ergonômicos, gerados principalmente pela postura irregular dos profissionais de enfermagem em situações como movimentações de pacientes, flexões da coluna frequentes, entre outros. Já os riscos de acidentes são aqueles inerentes a cada ambiente de trabalho, como, por exemplo, risco de queda decorrente de pisos ou iluminação inadequados (SESI-SEBRAE, 2005).

Sendo assim, para o desenvolvimento do presente trabalho foi convencionado que o conceito de riscos físicos deve ser representado por fatores ou agentes existentes no ambiente de trabalho que podem afetar a saúde dos trabalhadores, como: ruídos, vibrações, radiações, frio, calor, pressões anormais e umidade (SESI-SEBRAE, 2005). Para efeito de qualificação de cada um desses cenários considerou-se:

- Vibração: como sendo produzida por máquinas e equipamentos específicos, com o passar do tempo e sem a devida proteção, o trabalhador poderá sofrer danos nas articulações, dores na coluna, disfunção renal e circulatória.

- Radiação: como sendo originária da ultravioleta, provocada por soldas elétricas, por exemplo, pode ocasionar lesões oculares e queimaduras. As ionizantes, advindas de materiais radioativos, podem provocar anemias, leucemia e até outros tipos de câncer.

- Ruído: gerada em níveis excessivos, os ruídos advindos no local de trabalho, ao longo do tempo podem provocar alterações auditivas, que vão desde a perda parcial até a surdez total.

- Calor: Os trabalhadores expostos a atividades de fundição, siderurgia, indústrias de vidro a céu aberto e outras, são os mais propensos a problemas como insolação, câimbras e, em alguns casos, problemas com o cristalino do globo ocular, mais conhecidos como catarata. 
- Frio: Os casos mais comuns de doenças que se destacam pela ação do frio são as queimaduras pelo frio, gripes, inflamações das amígdalas e da laringe, resfriados, algumas alergias, congelamento nos pés e mãos e problemas circulatórios.

- Umidade: As atividades ou operações executadas em locais alagados ou encharcados, com umidade excessiva, poderão ser capazes de produzir danos à saúde dos trabalhadores, como frieiras e micoses, dentre outras.

Como riscos físicos, também, foram considerados os aspectos ergonômicos ligados à execução de tarefas, à organização e às relações de trabalho, ao esforço físico intenso, levantamento e transporte manual de peso, mobiliário inadequado, posturas incorretas, controle rígido de tempo para produtividade, imposição de ritmos excessivos, trabalho em turno e noturno, jornadas de trabalho prolongadas, monotonia, repetitividade e situações causadoras de estresse (SESI-SEBRAE, 2005).

\section{METODOLOGIA}

O presente artigo tem como objetivo o mapeamento dos riscos físicos, aos colaboradores na atividade do cultivo de manga na cidade de Ipanguaçu, por meio da Análise Preliminar de Riscos. Para tanto, foi utilizada a estratégia de pesquisa de natureza qualitativa, classificada também como descritiva, bem como exploratória, e que utilizou para o desenvolvimento de seu processo a técnica do estudo de caso.

O estudo de caso que segundo Yin (2005), representa uma investigação empírica e compreende um método abrangente, com a lógica do planejamento, da coleta e da análise de dados e da escolha do referencial teórico. Pode incluir tanto estudos de caso único quanto de múltiplos, assim como abordagens quantitativas e qualitativas de pesquisa.

Primeiramente, foram coletados os dados referentes ao cultivo da manga, dados estes que consistiram no levantamento das etapas e das funções relacionadas a este cultivo. Posteriormente foi feito um levantamento dos riscos físicos, bem como a causa/fonte geradora e possíveis danos à saúde, em seguida, foram definidos os mecanismos de prevenção, controle e/ou eliminação dos mesmos. A técnica escolhida para análise dos riscos físicos associados a atividade foi a APP, visto que atende aos requisitos mínimos estabelecidos por Camacho (2005) para utilização desta.

As fontes adotadas no estudo foram levantadas através de livros, internet e artigos publicados, os quais auxiliaram no entendimento do tema abordado. O estudo realizado evidenciou a utilidade da técnica de análise de riscos.

\section{RESULTADOS E DISCUSSÕES}

Considerando o levantamento inicial de campo foi possível desenvolver um descritivo acerca das atividades que envolvem o cultivo da manga e correlacionados os fatores de riscos físicos e ergonômicos associados ao seu desenvolvimento, e estas serão descritas a seguir. 
O processo é iniciado pela atividade de preparação do solo. Essas operações são feitas três a quatro meses antes do plantio e consiste na roçagem, destocamento da área. Em seguida procede-se a coleta de amostras do solo para posterior análise, visando avaliar a necessidade de calagem e fertilização. Caracterizam-se pelas operações de aração, gradagem leve e/ou pesada, ou qualquer outra visando o preparo do solo, deverá ser definida em função das condições da área a ser preparada. Nessa atividade foram mapeados como os principais riscos físicos o calor, as radiações não ionizantes (exposição ao sol) e o ruído (em função da operação de motores e implementos agrícolas).

$\mathrm{Na}$ segunda etapa do processo tem-se o plantio e replantio das mudas, que são realizados de forma manual. Após a determinação do espaçamento a ser utilizado, realiza-se a abertura das covas e posterior plantio. Nessa etapa a exposição dos colaboradores se dá aos efeitos do calor e de radiações não ionizantes (exposição excessiva ao sol).

Na sequencia é realizada a eliminação de plantas invasoras. O controle das plantas invasoras tem como objetivo reduzir a competição por luz, água nutrientes bem como diminuir o número de plantas hospedeiras de pragas e doenças. O controle é realizado de forma manual (enxadas), utilizando roçadeiras e com aplicações de herbicidas. A exposição ocorre a efeitos do calor e radiações não ionizantes (exposição excessiva ao sol).

As etapas seguintes seguem da poda, adubação, indução floral e irrigação. A poda é realizada com objetivo de orientar a forma das plantas em função do meio, espécie, vigor da variedade e da porta-enxerto; manter um crescimento vegetativo equilibrado nas diferentes partes da planta; conservar o equilíbrio entre raízes e a parte aérea, para regular o vigor e a produção das plantas e facilitar a aeração e iluminação da copa. A poda é feita de forma manual e mecanizada. A prática de fornecimento de adubos ou fertilizantes ao solo, de modo a recuperar ou conservar a sua fertilidade, suprindo a carência de nutrientes e proporcionando o pleno desenvolvimento das culturas vegetais. E é utilizada a indução floral com objetivo de que a planta produza em qualquer época do ano, através da utilização de um fitoregulador, que faz com que a planta paralise seu crescimento, acumulando reservas. A partir daí, é feita uma modificação celular e ao invés de ter células vegetativas, a planta produz mais células reprodutivas. Com essa modificação e com a aplicação do nitrato, é desencadeado o processo de floração e a produção fora do tempo. De acordo com a necessidade hídrica da cultura aliado aos dados de precipitações, é realizado o fornecimento controlado de água para as plantas em quantidade suficiente e no momento certo, assegurando a produtividade e a sobrevivência da plantação, através do sistema de irrigação por gotejamento. Nessas quatro etapas os colaboradores ficam expostos ao calor e radiações não ionizantes (exposição excessiva ao sol).

O processo segue com as etapas intermitentes de monitoramento integrado de pragas e pulverizações eventuais, que tem na sua essência riscos associado a produtos químicos, entretanto, que não serão explorados na análise desse artigo.

Por fim, é realizada colheita dos frutos, feita manualmente pelos trabalhadores rurais, com o auxílio de tesouras é feito o corte do pedúnculo com cerca de $2 \mathrm{~cm}$ de comprimento para evitar o derramamento de látex. Os frutos são acondicionados em contentores com capacidade para $20 \mathrm{~kg}$, posteriormente transportados em carritelas para o packing house. 
Nas etapas após o processo produtivo tem-se o processamento dos produtos obtidos, nos chamados packing house. Nessa etapa tem-se o seguinte cenário:

- Recepção: Todo lote de manga que chega à plataforma de recepção está devidamente identificada com nome do produtor, área colhida, dia e quantidade de contentores, sendo descarregados e levados até o pátio de recepção de frutos. O auxiliar de controle de qualidade através de amostragem realiza análise física da fruta, bem como avaliação do grau Brix e coloração. Riscos Físicos: Ruído (funcionamento de máquinas e motores), calor.

- Limpeza e pré-seleção: É feita a despedunculagem dos frutos, com posterior imersão em solução para cessar a exsudação de látex. Os frutos sem valor comercial, imaturos, deformados, com maturidade avançada e com outros defeitos aparentes são separados e retirados do processo. Riscos Físicos: Ruído (funcionamento de máquinas e motores).

- Classificação: Após passarem por jatos de água, e secagem a quente, os frutos passam pelo sistema de classificação, onde são separados segundo suas características de peso, para que no momento da embalagem, todos possuam o mesmo tamanho (calibre). Riscos Físicos: Ruído (funcionamento de máquinas e motores).

- Tratamento hidrotérmico: Caso o produto seja destinado ao mercado Americano, deverá passar pelo tratamento hidrotérmico, que consiste na imersão dos frutos em água a aproximadamente $47,5^{\circ} \mathrm{C}$ por um tempo de 90 minutos. Riscos Físicos: Ruído (funcionamento de máquinas e motores).

- Tratamento Pós-colheita: O auxiliar de controle de qualidade prepara a solução de cera e fungicida, que são aplicados aos frutos através dos bicos de aspersão. A aplicação da cera tem a finalidade de melhorar a aparência do fruto e diminuir a taxa de transpiração. O fungicida age no controle de doenças pós-colheita. Riscos Físicos: Ruído (funcionamento de máquinas e motores).

- Montagem e transporte de caixas: As caixas de papelão são montadas e dispostas na monovia (transportadora de caixas aéreas) para serem utilizadas no processo de embalagem. Riscos Físicos: Ruído (funcionamento de máquinas e motores).

- Embalagem e Paletização: Os frutos são embalados por trabalhadores rurais em caixas de papelão (não reciclado) para proteger contra danos mecânicos e permitir a ventilação. As caixas são dispostas na monovia, e em seguida procede-se a paletização, (onde as caixas são empilhadas sobre estrado de madeira (pallets) em colunas, somando um total de 252 caixas), assim são ladeadas por cantoneiras de papelão e amarradas com fita nylon. Riscos Físicos: Ruído (funcionamento de máquinas e motores).

- Pré-resfriamento: Os auxiliares de controle de qualidade levam os pallets para os túneis de resfriamento, os quais estão a uma temperatura que varia de $29^{\circ} \mathrm{C}$ a $31^{\circ} \mathrm{C}$, onde ficam até atingirem a temperatura de $10^{\circ} \mathrm{C}$ na polpa. Riscos Físicos: Frio (entrada em câmara fria).

- Armazenamento: Os pallets são armazenados em câmara fria para aguardarem a ovação, estando à temperatura regulada entre $10^{\circ} \mathrm{C}$ a $10,5^{\circ} \mathrm{C}$ e a umidade relativa de 85 a 95\%. Riscos Físicos: Frio (entrada em câmara fria). 
- Expedição: Os auxiliares de controle de qualidade fazem o carregamento dos containers nas docas, com temperatura ideal de $10^{\circ} \mathrm{C}$, onde posteriormente são transportados até o porto de destino. Riscos Físicos: Frio (entrada em câmara fria).

Contudo, tem-se o cenário da produção e beneficiamento dos frutos. Desse cenário foram analisadas as condições de riscos e geradas as orientações necessárias ao gerenciamento dos riscos ocupacionais da atividade.

Através do mapeamento dos riscos físicos, a que os colaboradores estão expostos, foi possível elaborar a Tabela 3. Para cada etapa do processo produtivo da manga, os riscos correspondentes são descritos, bem como, as categorias de frequência, de gravidade, de severidade e de riscos.

Tabela 3 - Descrição das etapas/atividades/riscos físicos/categorias de frequência, severidade de riscos.

\begin{tabular}{|c|c|c|c|c|}
\hline Etapas & $\begin{array}{c}\text { Descrição das atividades } \\
\text { desenvolvidas }\end{array}$ & Riscos físicos & $\begin{array}{c}\text { Categoria de } \\
\text { frequência }\end{array}$ & $\begin{array}{c}\text { Categoria de } \\
\text { severidade }\end{array}$ \\
\hline $\begin{array}{l}\text { Preparo de } \\
\text { solo }\end{array}$ & Gradagem, aração, calagem & Calor & C & III \\
\hline $\begin{array}{l}\text { Preparo de } \\
\text { solo }\end{array}$ & $\begin{array}{c}\text { Gradagem, aração e } \\
\text { calagem }\end{array}$ & Ruído & C & III \\
\hline $\begin{array}{l}\text { Preparo de } \\
\text { solo }\end{array}$ & $\begin{array}{l}\text { Gradagem, aração e } \\
\text { calagem }\end{array}$ & $\begin{array}{l}\text { Radiação não } \\
\text { ionizante }\end{array}$ & C & III \\
\hline Plantio & Plantio de mudas & Calor & C & III \\
\hline Replantio & Replantio de mudas & Calor & $\mathrm{C}$ & III \\
\hline $\begin{array}{c}\text { Tratos } \\
\text { culturais }\end{array}$ & $\begin{array}{c}\text { Eliminação de plantas } \\
\text { invasoras }\end{array}$ & Calor & C & III \\
\hline $\begin{array}{c}\text { Tratos } \\
\text { culturais }\end{array}$ & $\begin{array}{c}\text { Eliminação de plantas } \\
\text { invasoras }\end{array}$ & $\begin{array}{l}\text { Radiação não } \\
\text { ionizante }\end{array}$ & C & III \\
\hline $\begin{array}{c}\text { Tratos } \\
\text { culturais }\end{array}$ & Podas & Calor & C & III \\
\hline $\begin{array}{c}\text { Tratos } \\
\text { culturais }\end{array}$ & Podas & $\begin{array}{c}\text { Radiação não } \\
\text { ionizante }\end{array}$ & C & III \\
\hline $\begin{array}{c}\text { Tratos } \\
\text { culturais }\end{array}$ & Adubação & Calor & C & III \\
\hline $\begin{array}{c}\text { Tratos } \\
\text { culturais }\end{array}$ & Adubação & $\begin{array}{l}\text { Radiação não } \\
\text { ionizante }\end{array}$ & C & III \\
\hline $\begin{array}{l}\text { Tratos } \\
\text { culturais }\end{array}$ & Indução floral & Calor & C & III \\
\hline
\end{tabular}




\begin{tabular}{|c|c|c|c|c|}
\hline $\begin{array}{l}\text { Tratos } \\
\text { culturais }\end{array}$ & Indução floral & $\begin{array}{l}\text { Radiação não } \\
\text { ionizante }\end{array}$ & C & III \\
\hline $\begin{array}{c}\text { Tratos } \\
\text { culturais }\end{array}$ & Irrigação & Calor & C & III \\
\hline $\begin{array}{l}\text { Tratos } \\
\text { culturais }\end{array}$ & Irrigação & Umidade & C & III \\
\hline Manejo & $\begin{array}{l}\text { Monitoramento } \\
\text { fitossanitário }\end{array}$ & Calor & C & III \\
\hline Manejo & $\begin{array}{l}\text { Monitoramento } \\
\text { fitossanitário }\end{array}$ & Ruído & C & III \\
\hline $\begin{array}{l}\text { Manejo da } \\
\text { cultura }\end{array}$ & Pulverizações & Ruído & C & III \\
\hline $\begin{array}{l}\text { Manejo da } \\
\text { cultura }\end{array}$ & Pulverizações & Umidade & C & III \\
\hline $\begin{array}{l}\text { Manejo da } \\
\text { cultura }\end{array}$ & Colheita & Calor & C & III \\
\hline $\begin{array}{l}\text { Manejo da } \\
\text { cultura }\end{array}$ & Colheita & Ruído & C & III \\
\hline $\begin{array}{l}\text { Packing } \\
\text { House }\end{array}$ & Recepção da fruta & Ruído & C & III \\
\hline $\begin{array}{l}\text { Packing } \\
\text { House }\end{array}$ & Limpeza e pré seleção & Ruído & C & III \\
\hline $\begin{array}{l}\text { Packing } \\
\text { House }\end{array}$ & Classificação dos frutos & Ruído & C & III \\
\hline $\begin{array}{l}\text { Packing } \\
\text { House }\end{array}$ & Tratamento Hidrotérmico & Ruído & C & III \\
\hline $\begin{array}{l}\text { Packing } \\
\text { House }\end{array}$ & Tratamento pós-colheita & Ruído & C & III \\
\hline $\begin{array}{l}\text { Packing } \\
\text { House }\end{array}$ & $\begin{array}{l}\text { Montagem e transporte de } \\
\text { caixas }\end{array}$ & Ruído & C & III \\
\hline Packing & Embalagem e paletização & Ruído & C & III \\
\hline
\end{tabular}




\begin{tabular}{|c|c|c|c|c|}
\hline House & & & \\
\hline $\begin{array}{c}\text { Packing } \\
\text { House }\end{array}$ & Pré-resfriamento & Frio & $\mathrm{C}$ & III \\
\hline $\begin{array}{c}\text { Packing } \\
\text { House }\end{array}$ & Armazenamento & Frio & $\mathrm{C}$ & III \\
\hline $\begin{array}{c}\text { Packing } \\
\text { House }\end{array}$ & Expedição & Frio & $\mathrm{C}$ & III \\
\hline
\end{tabular}

Com base na Tabela 3 as categorias de frequência e severidade são respectivamente $C$ (frequência ocasional) e III (severidade marginal) para todas as etapas. Portanto, ao se fazer o cruzamento dessas categorias na Matriz de Risco constante na Figura 2, observa-se que os cenários estão fora da área hachurada. Tendo-se uma fragilidade dessa metodologia ao eleger a priorização para os recursos e elementos de gestão a serem adicionados a tais organizações.

Entretanto, mesmo estando fora da área hachurada, é interessante que algumas medidas de prevenção/mitigação, dos perigos citados a cima, sejam adotadas a fim de tornar as condições/ambiente de trabalho mais confortáveis para os colaboradores. Abaixo seguem os danos, bem como as medidas de proteção para a mitigação dos riscos físicos identificados na atividade de cultivo da manga.

Nessa leitura e orientações de medidas mitigadoras, tem-se que o ruído age diretamente sobre o sistema nervoso e pode ocasionar fadiga nervosa, alterações mentais (perda de memória, irritabilidade, dificuldade em coordenar ideias), hipertensão, modificação do ritmo cardíaco, modificação do calibre dos vasos sanguíneos, modificação do ritmo respiratório, perturbações gastrointestinais, diminuição da visão noturna, dificuldade na percepção de cores, bem como perda temporária ou definitiva da audição.

Logo, para evitar ou diminuir os danos provocados pelo ruído no local de trabalho devem ser adotadas as seguintes medidas (o que usualmente não são observadas nas empresas visitadas para a referida região), conforme descreve Saliba (2011):

- Medidas de proteção coletiva - enclausuramento da máquina produtora de ruído; isolamento de ruído.

- Medida de proteção individual - fornecimento de equipamento de proteção individual (EPI) (no caso, protetor auricular). O EPI deve ser fornecido na impossibilidade de eliminar o ruído ou como medida complementar.

- Medidas médicas - exames audiométricos periódicos, afastamento do local de trabalho, revezamento.

- Medidas educacionais - orientação para o uso correto do EPI, campanha de conscientização.

- Medidas administrativas - tornar obrigatório o uso do EPI: controlar seu uso. 
Para o caso da radiação não ionizante, que produz efeitos, quais sejam: perturbações visuais (conjuntivites, cataratas), queimaduras, lesões na pele, etc. Portanto, as seguintes medidas de controle, recomendadas por Saliba (2011) devem ser atendidas:

- Medidas de proteção individual - fornecimento de EPI adequado ao risco (ex: filtro solar resistente à água e à transpiração, chapéu de abas largas e que proteja a nuca, farda de algodão e com mangas, óculos de sol com filtragem de ultravioleta), ingestão água.

- Medida administrativa - (ex: definir horário de trabalho que evitem a exposição solar das 11 às 15 horas).

- Medida médica - exames periódicos.

No tocante ao calor, que pode provocar a desidratação, erupção da pele, câimbras, fadiga física, distúrbios psiconeuróticos, problemas cardiocirculatórios e insolação. E para o frio, por sua vez, pode causar feridas, rachaduras e necrose na pele, enregelamento (ficar congelado), agravamento de doenças reumáticas, predisposição para acidentes, predisposição para doenças das vias respiratórias deve-se adotar as seguintes ações, segundo SESI-SEBRAE (2005):

- Medidas de proteção coletiva - ventilação local exaustora, quando puder existir, com a função de retirar o calor e gases dos ambientes, isolamento das fontes de calor/frio.

- Medidas de proteção individual - fornecimento de EPI (ex: avental, bota, capuz, luvas especiais para trabalhar no frio) e manter a pele hidratada.

Diante desse quadro, o cenário proposto consiste numa contribuição a formatação dos programas legais de gerenciamento de riscos ambientais, com uma rota de qualificação, priorização e medidas mitigadoras para composição desses programas.

\section{CONSIDERAÇÕES FINAIS}

O cultivo da manga, assim como outras culturas, é realizado em locais de trabalho que pela própria natureza da atividade desenvolvida podem comprometer a saúde e segurança do trabalhador em curto, médio e longo prazo, provocando lesões imediatas, doenças ou a morte. Desta forma, em qualquer tipo de atividade laboral, torna-se imprescindível a necessidade de investigar o ambiente de trabalho para conhecer os riscos a que estão expostos os colaboradores. Nesse trabalho, elencou-se tais elementos críticos no cultivo e processamento primário da manga, obtendo-se o mapeamento e um conjunto de medidas associadas ao abatimento dos riscos de acidentes associados a tais atividades.

A técnica de Análise Preliminar de Perigos auxiliou no alcance do objetivo almejado por esse artigo, porém, teve uma séria limitação na priorização dos cenários e escolha para os casos de maior esforço monetário e de gestão para os casos levantados.

O levantamento dos riscos físicos envolvidos na atividade do cultivo da manga, em caso específico para a região do alto oeste potiguar, evidenciou por meio da interpretação da Matriz de Risco que os riscos que a maioria dos itens levantados ocorrem ocasionalmente e não causam grandes danos ao colaborador, à empresa e ao meio ambiente. 
Entretanto, como contribuição à saúde e bem estar dos colaboradores foram indicadas algumas medidas mitigadoras e de prevenção aos riscos ambientais associados a tal atividade, tais como: uso de protetor solar, maior ingestão de água, enclausuramento de máquinas geradoras de ruído, fornecimento e uso adequado do EPI, exames periódicos, dentre outras.

\section{REFERÊNCIAS BIBLIOGRÁFICAS}

1. ALENCAR, L. Metodologias de análise de riscos: APP e HAZOP. Rio de Janeiro: UFRJ, 2009, 30f. Disponível em <http://www.saneamento.poli.ufrj.br>. Acesso em 21/06/2012.

2. ALMEIDA, W. F. De. Trabalho Agrícola e sua Relação com Saúde/Doença. Rio de Janeiro, 1995.

3. AYRES, D. de O.; CORRÊA, J. A. P. Manual de Prevenção de Acidentes do Trabalho. São Paulo, Editora ATLAS, 2001.

4. CAMACHO, E. N. Uma Proposta de Metodologia para Análise Quantitativa de Riscos Ambientais. (2004). Tese - Programa de Pós-graduação de Engenharia, Universidade Federal do Rio de Janeiro, 2004.

5. COUTO, J. L. V. do. Segurança no trabalho rural (2007). Disponível em: <http://www.ufrrj.br/institutos/it/de/acidentes/acidente.htm > Acesso em: 2 de julho de 2012.

6. EMBRAPA. Disponível em <http://sistemasdeproducao.cnptia.embrapa.br>. Acesso em $21 / 06 / 2012$.

7. MARINO, S. Porque o transporte é o elo fraco na cadeia de distribuição de hortifrútis. Revista Tecnologística, 2002.

8. MINISTÉRIO DA SAÚDE DO BRASIL. Doenças relacionadas ao trabalho: manual de procedimentos para serviços de saúde. Ministério da Saúde do Brasil, Representação no Brasil da OPS/OMS. Brasília: Ministério da Saúde, 2001.

9. MINISTÉRIO DO TRABALHO E EMPREGO. Portaria no 3.214, de 08 de junho de 1978. NR6: Equipamento de proteção individual, Brasília, DF, 2012.

10. MINISTÉRIO DO TRABALHO E EMPREGO. Portaria $\mathrm{n}=3.214$, de 08 de junho de 1978. NR31: Segurança e saúde no trabalho na agricultura, pecuária silvicultura, exploração florestal e aqüicultura, Brasília, DF, 2012.

11. RAMOS, S. Y. Avaliação da localização de Packing houses no Estado de São Paulo: o caso da laranja de mesa. Piracicaba/SP, 2001. 132 f. Dissertação (Mestrado em Ciências) Universidade de São Paulo.

12. SALIBA, T. M. Curso Básico de Segurança e Higiene Ocupacional. 4. ed. São Paulo: LTR, 2011. 
13. SESI-SEBRAE. Dicas de Prevenção de Acidentes e Doenças no Trabalho. SESI SEBRAE, Saúde e Segurança no Trabalho : Micro e Pequenas Empresas / Luiz Augusto Damasceno Brasil (org.). - Brasília: SESI-DN, 2005.

14. SHERIQUE, Jaques. Aprenda como fazer: PRRA, PCMAT E MRA. São Paulo: LTR, 2004.

15. SILVA, J. R. et al. Protocolo de ações preventivas aos riscos ocupacionais presentes em indústrias de produção sucroalcooleira. Revista Eletrônica de Enfermagem do Centro de Estudos de Enfermagem e Nutrição [serial on-line] 2011 ago-set 2(2):1-16. Available from: <http://www.ceen.com.br/revistaeletronica>.

16. YIN, R. Estudo de caso: planejamento e métodos. Porto Alegre: Bookman, 2005. 